\title{
Zoneamento Ambiental da Microbacia Hidrográfica do Açude Caripina no Município de Riacho de Santana, RN
}

\author{
Environmental Zoning of the Caripina Reservoir in the Municipality of Riacho de Santana, RN
}

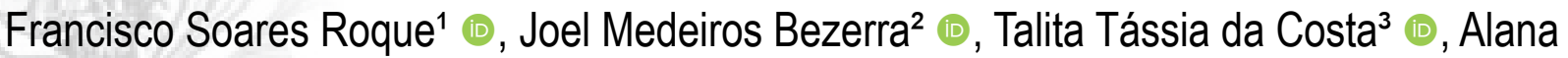 Ticiane Alves do Rêgo ${ }^{3}$ (), Ricassilly Isac Bruno Rufino Lima $^{2}$ (), Rafael Silva de Souza ${ }^{4}$ (), Antonio Batista de Queiroz Júnior ${ }^{3}$ (1) \& Helves Clerverton Guerra Costa ${ }^{2}$}

\author{
1 Universidade Federal do Rio Grande do Norte, Programa de Pós-Graduação em Engenharia Sanitária e Ambiental, Natal, RN, \\ Brasil \\ ${ }^{2}$ Universidade Federal Rural do Semi-Árido, Campus Pau dos Ferros, Departamento de Engenharias e Tecnologia, Pau dos Ferros, \\ RN, Brasil \\ ${ }^{3}$ Universidade do Estado do Rio Grande do Norte, Faculdade de Ciências Exatas e Naturais, Programa de Pós-Graduação em \\ Ciências Naturais, Mossoró, RN, Brasil \\ 4 Universidade do Estado do Rio Grande do Norte, Faculdade de Filosofia e Ciências Sociais, Departamento de Geografia, Mossoró, \\ RN, Brasil \\ E-mails: fabiokand@gmail.com; joel.medeiros@ufersa.edu.br; talitatcosta@hotmail.com; alana_ticiane10@hotmail.com; \\ ricassilly@hotmail.com; rafael2100cruzada@hotmail.com; antonio.queiroz17@gmail.com; helves.guerra5@gmail.com
}

\section{Resumo}

O objetivo do trabalho foi realizar o zoneamento da Microbacia Hidrográfica do Açude Caripina de Riacho de Santana (MBHACRS), mediante análise morfométrica tendo como suporte os Sistemas de Informações Geográficas - SIG. Com o auxílio desses softwares, foram elaborados mapas temáticos e as análises foram realizadas de acordo com a Resolução CONAMA n 303/2002 e o Código Florestal Lei $\mathrm{N}^{\mathrm{o}}$ 12.651/2012. Classificou-se a rede de drenagem como de $3^{\mathrm{a}}$ ordem, o relevo predominante ondulado e declividade média entre 3 a $8 \%$. Observou-se a necessidade de delimitação de APP's de acordo com as legislações vigentes para cada tipo encostas, nascentes e entorno de lagos e lagoas naturais. A MBHACRS mostrou-se relevante para o desenvolvimento social e ambiental da região, tendo em vista que engloba o principal reservatório do município de Riacho de Santana - RN.

Palavras-chave: Gestão hídrica; Reservatório; Área de preservação permanente

\begin{abstract}
This research aimed to carry out the zoning of the Hydrographic Microbasin of the "Açude Caripina" of the city Riacho de Santana (MBHACRS), through morphometric analysis supported by Geographic Information Systems - GIS. With the aid of these software, thematic maps were elaborated and the analyses were carried out following the CONAMA Resolution No 303/2002 and the Forest Code law $\mathrm{N}^{\mathrm{o}} 12,651 / 2012$. The drainage network was classified as of $3^{\text {rd }}$ order, with the predominant wavy topography and average slope between 3 to $8 \%$. It is worth highlighting the need to define the PPA's following the current legislation for each type of slope, headwaters and surrounding lakes and natural lagoons. The MBHACRS proved to be relevant to the social and environmental development of the region, considering that it encompasses the main reservoir in the municipality of Riacho de Santana - RN.
\end{abstract}

Keywords: Water management; Reservoir; Permanent preservation area 


\section{Introdução}

O panorama do abastecimento hídrico evidencia uma situação preocupante quanto a quantidade, qualidade e disposição dos recursos hídricos no mundo e no Brasil. Diante este cenário, surge a necessidade de estabelecer medidas legais que regulem o uso da água (Rodrigues et al. 2016).

A Política Nacional de Recursos Hídricos - PNRH, que foi instituída pela Lei $\mathrm{N}^{\circ} 9.433 / 1997$, surge diante desse cenário, buscando assegurar a proteção e o uso sustentável das águas para seus múltiplos usos, como também o enquadramento dos corpos hídricos em classes (Política Nacional de Recursos Hídricos 1997).

A bacia hidrográfica consiste em uma unidade territorial de planejamento para a gestão dos Recursos Hídricos, com áreas de dimensões variadas, definidas de acordo com a forma topográfica, condições climáticas, características geológicas e geomorfológicas consistindo, assim, num sistema de curso de água ou drenagem interligado que descarrega este fluxo no único local denominado exutório (Farias \& Silva 2015). Na caracterização de uma bacia hidrográfica comumente observa-se o relevo, com a análise de parâmetros morfométricos como: altimetria, dimensões, desníveis e extensões, e quanto a morfologia em: formas do perfil, concavidades, convexidades, rupturas, topos e fundos de vale (Araújo 2017; Souza, Almeida \& Correia 2015).

Além disso, o uso e ocupação do solo, associado com a ocupação das Áreas de Preservação Permanente, conforme o código florestal Lei $\mathrm{N}^{\circ} 12.651 / 2012$, tal como a resolução CONAMA 303/2002, se apresentam como áreas frágeis ou susceptíveis em virtude da localização de zona urbana ou rural, como também as faixas nos quais os cursos de água estão inseridos.

Sendo assim, sua análise torna-se eficiente para o controle/conservação da qualidade e quantidade disponível de água devido a análise das alterações no ciclo hidrológico e no meio ambiente, e, consequentemente, prever formas de mitigar esses impactos (Lorenzon et al. 2015).

O geoprocessamento, com suas ferramentas metodológicas e aplicativas, tem se tornado uma técnica amplamente utilizada para o estudo das análises dessas características, já que consegue realizar levantamentos de diversos parâmetros que facilitam no prognóstico das áreas, modificações e condições de controle ambiental (Alves 2016).

A região nordeste é caracterizada por extensos períodos de estiagem, sobretudo, devido ao baixo índice pluviométrico e alto índice de evapotranspiração, como também pela presença de cursos d'água de pequena vazão e extensão, onde esses fatores associados resultam em um déficit hídrico em áreas com alta densidade demográfica (Bezerra 2016).
Diante da importância deste reservatório para a região Santanense potiguar, buscou-se nesse estudo zonear a Microbacia Hidrográfica do Açude Caripina de Riacho de Santana - RN (MBHACRS), mediante análise morfométrica, por meio do uso de Sistemas de Informações Geográficas - SIG's, como forma de construir os dados e parâmetros almejados, tal como delimitar as Áreas de Preservação Permanente (APP) desta microbacia.

\section{Metodologia}

\section{1 Área de Estudo}

A área de estudo compreende a Microbacia Hidrográfica do Açude Caripina de Riacho de Santana (MBHACRS), que se encontra situada no município de Riacho de Santana, na qual de acordo com a nova regionalização brasileira, elaborado pelo Instituto Brasileiro de Geografia e Estatística (2017), geograficamente, a área de estudo localiza-se na região imediata de Pau dos Ferros e na região intermediária de Mossoró. Quanto aos limites que perfazem a localidade investigada, apresenta proximidade com os municípios de Água Nova, José da Penha, Luís Gomes, Marcelino Vieira, Rafael Fernandes e Coronel João Pessoa (Figura 1).

De acordo com o Instituto de Desenvolvimento Sustentável e Meio Ambiente (2008), IDEMA, o município de Riacho de Santana/RN predomina o clima semiárido de tipo quente e com índices pluviométricos com média de $718,4 \mathrm{~mm} / \mathrm{ano}$, temperaturas que expressam máximas de $21^{\circ} \mathrm{C}$ e com cerca de 2,700 horas de insolação. Segundo o Banco de Dados de Informações Ambientais (2021), a MBHACRS apresenta um solo predominantemente do tipo Argissolo Vermelho-Amarelo e está situada entre porções dos maciços residuais sertanejos e depressão sertaneja setentrional, encaixado entre unidades geológicas de rochas tipo cristalinas.

\subsection{Procedimentos Metodológicos}

\subsubsection{Delimitação da Microbacia e Determinação dos Parâmetros Morfométricos}

Para análise da MBHACRS, inicialmente delimitouse o polígono de espelho d'água e ponto de exutório com o auxílio do software Google Earth. Para a delimitação da microbacia hidrográfica em estudo, utilizou-se como base uma camada do tipo raster do Modelo Digital de Elevação (MDE) obtida por meio do projeto TOPODATA, da qual possui uma resolução espacial de pixel de $30 \mathrm{~m}$, projeção UTM e elipsoide de referência datum horizontal SIRGAS 2000, zona 24 Sul, referente a folha 06S39_ZN. 


\section{Mapa da Região Imediata de Pau dos Ferros/RN}
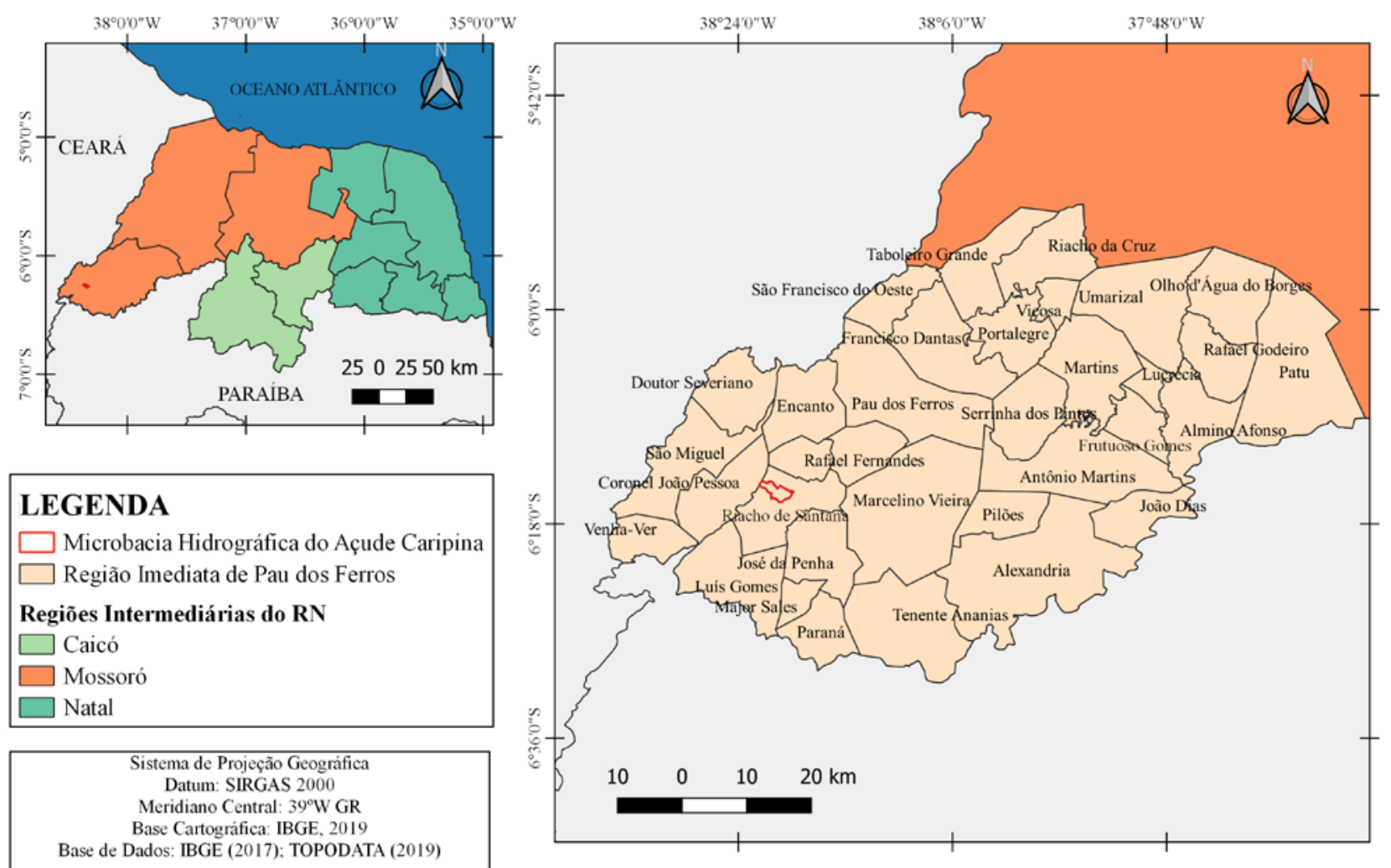
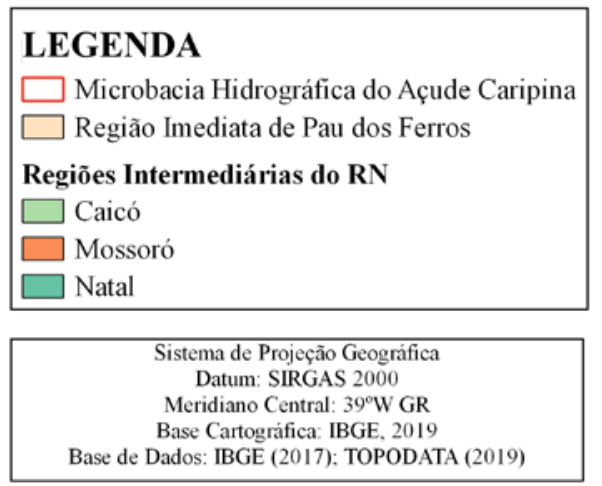

Figura 1 Regiões Intermediárias e Imediatas do Rio Grande do Norte.

Nesse sentido, os dados foram processados no Sistema de Informação Geográfica (SIG) de uso gratuito e de linguagem aberta (QGIS versão 3.4.8 LTR); para o tratamento das imagens utilizou-se as plataformas SAGA e GRASS, que consistem em um conjunto de ferramentas que possibilitam a delimitação de forma rápida, objetiva e eficiente de mapas.

Para delimitação da microbacia, a extração das informações da rede de drenagem e a direção do escoamento, utilizou o módulo r.watershed obtido junto ao algoritmo do GRASS. Para tanto, foi necessário inserir as coordenadas do ponto de exutório por meio do comando r.water. outlet. Posteriormente, realizou-se a conversão do raster da microbacia e rede drenagem para vetor com o uso do comando r.to.vect, como também a realização da suavização do efeito desta conversão por meio do v.generalize.

Em posse do mapa de drenagem, realizou-se a caracterização morfométrica da MBHACRS através das características geométricas, de relevo e da rede de drenagem (Tabela 1). Para a identificação da hierarquia fluvial utilizou-se a classificação proposta por Strahler (1957).

\subsubsection{Delimitação de Áreas de Preservação Permanentes da Microbacia}

Para a delimitação das Áreas de Preservação Permanente (APP's) da MBHACRS, tomou-se como referência o novo Código Florestal Brasileiro, Lei ${ }^{\circ}$ 12.651/2012 (Código Florestal 2012), como também a Resolução CONAMA no 303/2002, que dispõem sobre parâmetros, definições e limites destas áreas em questão.

Após o acesso aos dados vetoriais do local de estudo, deu-se prosseguimento a seleção e recorte de cada camada vetorial para área em delimitação, e, com o auxílio do software Google Earth, obteve-se imagens de satélites que possibilitaram fazer a amostragem para identificação da largura da calha dos rios da rede de drenagem.

\section{a) Corpos Hídricos}

Diante da efemeridade dos cursos d'água que permeiam a microbacia, a Lei 12.651/2012 não obriga APP's para as faixas marginais de cursos d'agua com essas características, em zonas rurais ou urbanas. Assim, não houve delimitação para esses elementos. 
Tabela 1 Parâmetros morfométricos a serem avaliados na MBHACRS

\begin{tabular}{|c|c|c|}
\hline \multicolumn{2}{|c|}{ Características Geométricas } & Equação \\
\hline Área de drenagem $(\mathrm{A})$ & $\begin{array}{l}\text { Área plana (projeção horizontal) inclusa entre seus divisores } \\
\text { topográficos }\left(\mathrm{km}^{2}\right) \text {. }\end{array}$ & $A$ \\
\hline Perímetro da bacia $(\mathrm{P})$ & $\begin{array}{l}\text { Linha imaginária que delimita a bacia através de um divisor de águas } \\
\text { principal }(\mathrm{km}) \text {. }\end{array}$ & $P$ \\
\hline Fator de forma $\left(F_{f}\right)$ & $\begin{array}{l}\text { Em que: A é a área de drenagem da bacia }\left(\mathrm{km}^{2}\right) \text { e L o comprimento do } \\
\text { curso d'água principal da bacia }(\mathrm{km}) \text {. Sendo avaliado conforme Villela \& } \\
\text { Mattos (1975). }\end{array}$ & $K_{f}=\frac{A}{L^{2}}$ \\
\hline Coeficiente de compacidade (Kc) & $\begin{array}{l}\text { Relaciona o perímetro da bacia com o perímetro de uma circunferência } \\
\text { de área igual à da bacia, em que quanto mais próximo de } 1 \text {, mais } \\
\text { circular será a bacia e maior será sua capacidade de proporcionar } \\
\text { grandes cheias (Mello \& Silva 2013). }\end{array}$ & $K_{c}=0,28 \cdot \frac{P}{\sqrt{A}}$ \\
\hline Índice de circularidade (IC) & $\begin{array}{l}\text { Tende para a unidade à medida que a bacia se aproxima da forma } \\
\text { circular e diminui à medida que a bacia tende a forma alongada (Tonello } \\
\text { et al. 2006). }\end{array}$ & $I_{C}=\frac{12,57 A}{P^{2}}$ \\
\hline \multicolumn{3}{|c|}{ Características do Relevo } \\
\hline $\begin{array}{l}\text { Altitudes máxima e mínima da microbacia } \\
\text { e maior e menor altitude do canal principal } \\
\left(\mathrm{H}_{\text {min; }} \mathrm{H}_{\text {máx }} \mathrm{HC}_{\text {max }}\right)\end{array}$ & As altitudes foram expressas em metros. & $\begin{array}{c}\mathrm{H}_{\text {min; }} \\
\mathrm{H}_{\text {máx; }} \\
\mathrm{HC}_{\text {máx; }} \\
\mathrm{HC}_{\min } \\
\end{array}$ \\
\hline Amplitude altimétrica $(\Delta \mathrm{H})$ & Diferença entre as altitudes máxima e mínima ocorrentes na bacia. & $\Delta \mathrm{H}=\mathrm{H}_{\max }-\mathrm{H}_{\min }$ \\
\hline Declividade média da bacia (I) & $\begin{array}{l}\text { Em que: I é a declividade média da bacia (\%); D a equidistância vertical } \\
\text { entre as curvas de nível (km); CN o comprimento total das curvas de } \\
\text { nível }(\mathrm{km}) \text {, conforme Mello \& Silva (2013). }\end{array}$ & $\mathrm{I}=\frac{\mathrm{D}}{\mathrm{A}}\left(\sum_{\mathrm{i}=1}^{\mathrm{n}} \mathrm{CN}_{\mathrm{i}}\right) 100$ \\
\hline $\begin{array}{l}\text { Declividade do curso d'água principal - } \\
\text { álveo }\left(I_{\mathrm{eq}}\right)\end{array}$ & $\begin{array}{l}\text { Em que: } I_{\text {eq }} \text { é declividade equivalente }\left(\mathrm{m} \mathrm{km}^{-1}\right) ; \Delta H \text { a amplitude } \\
\text { altimétrica do curso d'água principal }(\mathrm{m}) ; \text { e } L \text { é o comprimento do curso } \\
\text { d'água principal }(\mathrm{km}) \text {, utilizado por Bezerra et al. (2015). }\end{array}$ & $\mathrm{I}_{\mathrm{eq}}=\frac{\Delta \mathrm{H}}{\mathrm{L}}$ \\
\hline \multicolumn{3}{|c|}{ Características da rede de drenagem } \\
\hline Comprimento do curso d'água principal $(L)$ & Geralmente é expresso em km. & $\mathrm{L}$ \\
\hline Rede de drenagem $(\mathrm{Rd})$ & $\begin{array}{l}\text { Somatório dos comprimentos (em } \mathrm{km} \text { ) de todos os cursos d'água de } \\
\text { uma bacia hidrográfica, sejam eles: perenes, intermitentes ou efêmeros } \\
\text { - da bacia hidrográfica. }\end{array}$ & $\mathrm{Rd}=\Sigma \mathrm{Li}$ \\
\hline Densidade de drenagem (Dd) & $\begin{array}{l}\text { Em que: } \mathrm{Dd} \text { é a densidade de drenagem }\left(\mathrm{km} / \mathrm{km}^{2} \text { ou } \mathrm{m} / \mathrm{ha}\right), \mathrm{Rd} \text { a rede } \\
\text { de drenagem ( } \mathrm{km} \text { ou m) e A é a área de drenagem da bacia }\left(\mathrm{km}^{2} \text { ou em }\right. \\
\text { ha). Sendo classificado conforme Beltrame (1994). }\end{array}$ & $\mathrm{Dd}=\frac{\mathrm{Rd}}{\mathrm{A}}$ \\
\hline Ordem dos cursos d'água & $\begin{array}{l}\text { Utilizou-se neste trabalho a classificação apresentada por Strahler } \\
\text { (1957). }\end{array}$ & - \\
\hline $\begin{array}{l}\text { Extensão média do escoamento superficial } \\
(\mathrm{Cm})\end{array}$ & $\begin{array}{l}\text { Relaciona a densidade de drenagem da bacia hidrográfica com o } \\
\text { comprimento médio lateral da rede de drenagem. }\end{array}$ & $C_{m}=\frac{1}{4 \cdot D_{d}}$ \\
\hline Tempo de Concentração (Tc) & $\begin{array}{l}\text { É o tempo de percurso da água precipitada desde o ponto } \\
\text { cinematicamente mais afastado da bacia hidrográfica até a secção de } \\
\text { referência. } O \text { tempo de concentração (minutos) será calculado pela } \\
\text { fórmula de Kirpich Modificada, expressa por Rodrigues et al. (2016). } \Delta \mathrm{H} \\
\text { é a diferença de cotas nas extremidades do dreno principal. }\end{array}$ & $t_{c}=85,2 \cdot\left(\frac{L^{3}}{\Delta H}\right)^{0,385}$ \\
\hline Índice de Sinuosidade (Sin) & $\begin{array}{l}\text { Relação entre o comprimento do canal principal e a distância vetorial } \\
\text { entre os extremos do canal (Villela \& Mattos 1975). }\end{array}$ & $\operatorname{Sin}=\frac{L}{L_{t}}$ \\
\hline
\end{tabular}


Ainda, diante das acumulações artificiais de água na área de estudo, decorrentes de barramento ou represamento de cursos d'água naturais, as APP's devem ser definidas conforme consta na licença ambiental do empreendimento (Código Florestal 2012). Logo, a Resolução CONAMA n ${ }^{\circ}$ $303 / 2002$ complementa que para reservatórios artificiais não utilizados em abastecimento público ou geração de energia elétrica, com até vinte hectares e localizados em área rural, adota-se uma área com largura mínima de 15 metros de APP. Sendo assim, por meio da ferramenta Buffer aplicou-se a delimitação sugerida.

Para a delimitação das nascentes e olhos d'água que estão inseridos na microbacia, fez-se o uso do produto Junctions por meio dos dados do Filled Dem do TOPODATA, onde obteve-se as nascentes nos trechos de primeira ordem. Tendo como forma de encontrar a largura destas, foi gerada uma nova camada vetorial relativa à hidrografia, seguidamente com conhecimento destes estipulou-se as áreas de influência em torno dos pontos encontrados por meio da ferramenta Buffer.

Segundo a legislação vigente as áreas no entorno das nascentes e dos olhos d'água, qualquer que seja a sua situação topográfica, deve ter raio mínimo de 50 (cinquenta) metros em sua delimitação.

\section{b) Encostas}

Para a delimitação das APP's de encostas, utilizouse a camada do tipo raster do MDE para obtenção da declividade e altitude. Conforme estabelece a Lei $\mathrm{n}^{\circ}$ 12.651/2012, em seu capítulo II, Seção I, Art. $4^{\circ}$, parágrafo $\mathrm{V}$, são consideradas APP's as encostas ou parte destas que apresentem declividade superior a $45^{\circ}$, equivalente a $100 \%$ da linha de maior declive. Dessa forma, as áreas de interesse foram selecionadas e vetorizadas.

Posteriormente, as classes de declividade foram reclassificadas conforme valores estabelecidos pela Embrapa (1979), por meio do comando rreclass da extensão GRASS (Tabela 2).

Tabela 2 Classificação da declividade segundo Embrapa (1979)

\begin{tabular}{cc}
\hline Classes de Declividade (\%) & Relevo \\
\hline $0-3$ & Plano \\
$3-8$ & Relevo suavemente ondulado \\
$8-20$ & Relevo ondulado \\
$20-45$ & Revelo fortemente ondulado \\
$45-75$ & Revelo montanhoso \\
$>75$ & Revelo fortemente montanhoso \\
\hline
\end{tabular}

\section{Resultados e Discussão}

\subsection{Características Morfométricas da Microbacia Hidrográfica do Açude Caripina de Riacho de Santana}

A rede de drenagem da MBHACRS abrange apenas o município de Riacho de Santana (ver Figura 2). É situada entre as coordenadas de latitude S $568081.0 \mathrm{~m}$ e $9306478.2 \mathrm{~m}$, longitude O $577607.2 \mathrm{~m}$ e $9311141.7 \mathrm{~m}$, em projeção UTM, datum SIRGAS 2000, zona 24S. Com a sua delimitação, obteve-se área de $7,941 \mathrm{~km}^{2}$ e perímetro de $16,521 \mathrm{~km}$. A análise dessas variáveis relaciona-se a tendência de ocorrência de picos de enchentes no local, de forma que quanto maior a área da microbacia, menor será o risco de ocorrência destes eventos (Fraga et al. 2014).

De acordo com Rodrigues et al. (2016), os parâmetros morfométricos são fundamentais para a caracterização de uma bacia, devido sua relação com características fisiográficas. Na Tabela 3 exemplifica-se esses dados referentes a análise da MBHACRS.

A determinação da forma de uma bacia hidrográfica baseia-se nos índices que se relacionam com formas geométricas conhecidas, como o fator de forma $(\mathrm{F})$, coeficiente de compacidade $\left(\mathrm{K}_{\mathrm{c}}\right)$ e índice de circularidade $\left(\mathrm{I}_{\mathrm{C}}\right)$, onde, valores maiores de Ic são apresentados à medida que a bacia se aproxima da forma circular e diminuem conforme a mesma se torna mais alongada (Cardoso et al. 2006; Tonello et al. 2006). Na Tabela 3, verifica-se $I_{c}=0,366$ para área de estudo que indica que a MBHACRS possui forma pouca alongada, em concordância a delimitação expressa na Figura 2.

De acordo Vilela \& Mattos (1975), através das relações entre dados hidrológicos e características físicas de bacias, pode-se analisar o grau de risco de enchentes numa determinada precipitação. Sendo assim, os valores dos coeficientes de compacidade $\left(\mathrm{K}_{\mathrm{c}}=1,642\right)$ e fator de forma $\left(\mathrm{K}_{\mathrm{f}}=0,156\right)$ obtidos para a bacia em estudo, evidencia que a área em questão possui baixa propensão a grandes enchentes.

Em relação ao relevo da MBHACRS, estimouse para a menor altitude da microbacia $\left(\mathrm{H}_{\text {min }}\right)$ e do canal principal $\left(\mathrm{HC}_{\text {min }}\right)$ ambos o valor de $258,925 \mathrm{~m}$. Já para a maior altitude da microbacia $\left(\mathrm{H}_{\text {máx }}\right)$ e do canal principal $\left(\mathrm{HC}_{\text {máx }}\right)$, obteve-se, respectivamente, 797,305 m e 460,637 $\mathrm{m}$. Sendo assim, a diferença de cotas no dreno principal $(\Delta \mathrm{H})$ em estudo corresponde a 538,380 $\mathrm{m}$ e, com a análise da Figura 3, tem-se a equidistância de $50 \mathrm{~m}$ entre as curvas de nível. 


\section{Mapa de Delimitação da Microbacia Hidrográfica do Açude Caripina de} Riacho de Santana/RN
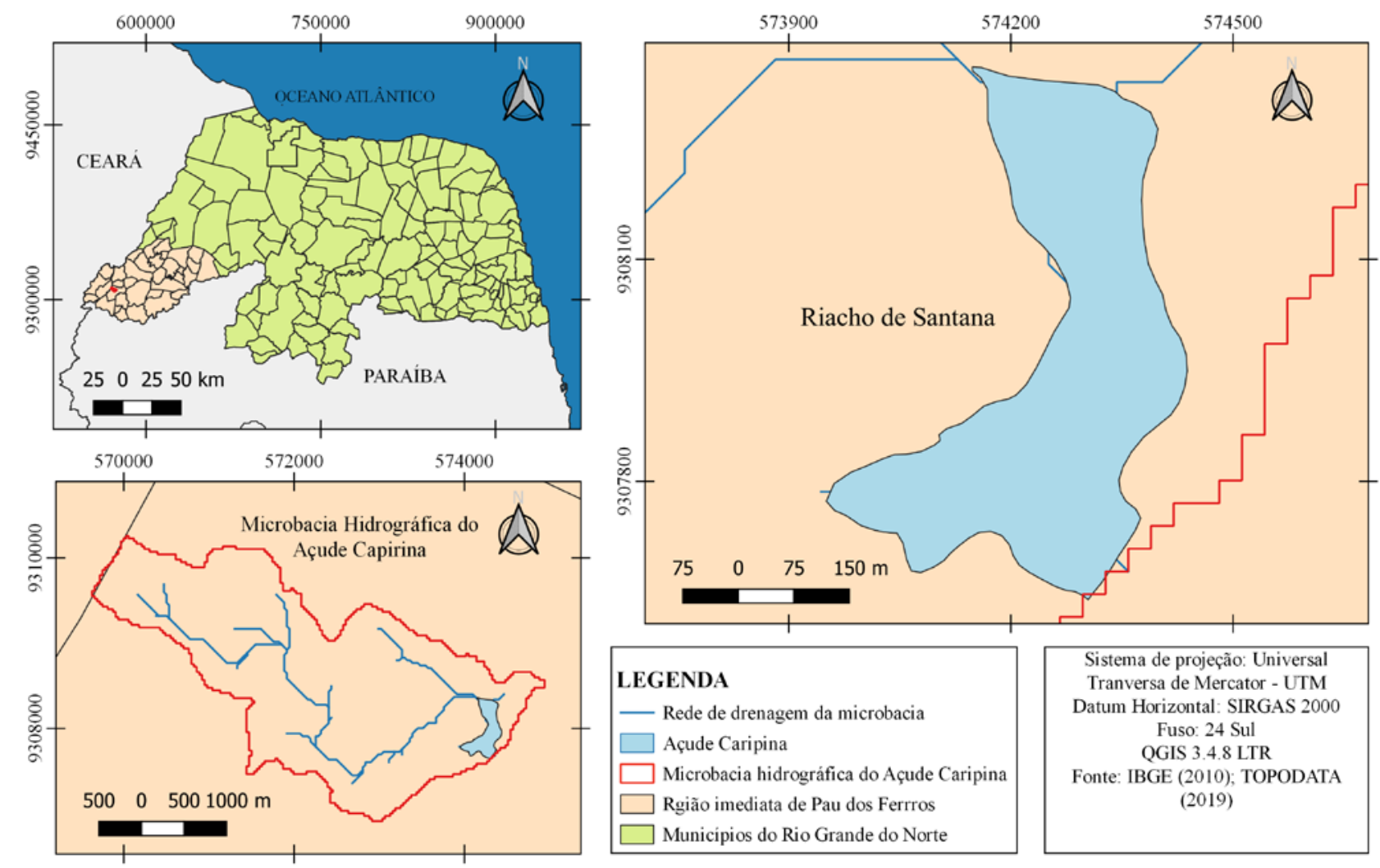

Figura 2 Delimitação da Microbacia Hidrográfica do Açude Caripina de Riacho de Santana/RN, contendo a divisão política dos municípios inseridos.

De acordo com metodologia de Strahler (1957), determinou-se que a microbacia é caracterizada com rede de drenagem de $3^{\mathrm{a}}$ ordem (Tabela 4). A Figura 4 indica que a MBHACRS possui poucas ramificações e a existência de um padrão similar a uma árvore, comumente denominado de perfil de drenagem dendrítico (Christofoletti 1970).

Com a análise das Tabelas 2 e 3 e a Figura 4, obteve-se o número de 31 drenos, o comprimento total da rede de drenagem $(\mathrm{Rd})$ de $12,763 \mathrm{~km}$ e uma densidade de drenagem (Dd) de 1,607 km/ $\mathrm{km}^{2}$, sendo assim, considerada de pouca drenagem (Santos et al. 2017). De acordo com Antoneli \& Thomaz (2007), o índice de sinuosidade de 1,552, expresso na Tabela 2, classifica a microbacia como forma transicional, já que quando este índice assume valores próximo de 1 , indica canais retilíneos, e para valores superiores a 2, canais tortuosos, entre esse intervalo, temse os canais transicionais.

\subsection{Delimitação da Declividade da MBHACRS}

Os cálculos dos parâmetros morfométricos da MBHACRS indicaram declividade média do curso d'água do canal principal de 75,48 m/km e declividade da microbacia de 18,08\%. Utilizando a classificação de relevo proposta por Embrapa (1979), obteve-se a Figura 5, que indica a predominância do relevo ondulado na microbacia.

Magalhães et al. (2020), ao realizarem estudo semelhante na Microbacia Hidrográfica do Açude Canafístula em Iracema - CE, diagnosticaram que a declividade média do curso d'água do canal principal foi de $0,03518 \mathrm{~km} / \mathrm{km}$ e a sua extensão de $15,46 \mathrm{~km}$ com declividade da microbacia de $11,51 \%$, onde é possível definir a possibilidade de alta velocidade de escoamento superficial. 
Tabela 3 Características morfométricas da MBHACRS

\begin{tabular}{|c|c|c|c|c|}
\hline Características & Parâmetros & Siglas & Unidades & Valores \\
\hline & Área da Bacia & $A$ & $\mathrm{~km}^{2}$ & 7,941 \\
\hline & Perímetro & $P$ & $\mathrm{~km}$ & 16,521 \\
\hline \multirow[t]{6}{*}{ Geométricas } & Coeficiente Compacidade & $K_{c}$ & - & 1,642 \\
\hline & Fator de Forma & $K_{f}$ & - & 0,156 \\
\hline & Índice de Circularidade & $I_{c}$ & - & 0,366 \\
\hline & Maior altitude da bacia & $H_{\text {máx }}$ & $\mathrm{m}$ & 797,305 \\
\hline & Maior altitude do canal principal & $H C_{\text {máx }}$ & $\mathrm{m}$ & 460,637 \\
\hline & Menor altitude da bacia & $H_{\min }$ & $\mathrm{m}$ & 258,925 \\
\hline \multirow[t]{8}{*}{ Relevo } & Menor altitude do canal principal & $H C_{\min }$ & $\mathrm{m}$ & 258,925 \\
\hline & Amplitude altimétrica & $\Delta H$ & $\mathrm{~m}$ & 538,380 \\
\hline & Declividade média da bacia & 1 & $\%$ & 18,083 \\
\hline & Declividade do curso d'água principal & $l_{\text {eq }}$ & $\mathrm{m} / \mathrm{km}$ & 75,467 \\
\hline & Ordem da bacia & - & ordem & $3^{a}$ \\
\hline & Número Total de Drenos & $N$ & unidade & 31 \\
\hline & Comprimento do curso d'água principal da bacia & $L$ & $\mathrm{~km}$ & 7,134 \\
\hline & Comprimento do Talvegue & $L_{t}$ & $\mathrm{~km}$ & 4,595 \\
\hline \multirow[t]{5}{*}{ Rede de Drenagem } & Índice de Sinuosidade & $\operatorname{Sin}$ & - & 1,552 \\
\hline & Rede de drenagem & $R_{d}$ & $\mathrm{~km}$ & 12,763 \\
\hline & Densidade de drenagem & $D_{d}$ & $\mathrm{~km} / \mathrm{km}^{2}$ & 1,607 \\
\hline & Densidade da Rede de Drenagem & $D_{r}$ & drenos $/ \mathrm{km}^{2}$ & 3,904 \\
\hline & Extensão média do escoamento Superficial & $C_{m}$ & $\mathrm{~km}$ & 0,156 \\
\hline
\end{tabular}

\section{Carta hipsométrica da Microbacia Hidrográfica do Açude Caripina de Riacho de Santana/RN}
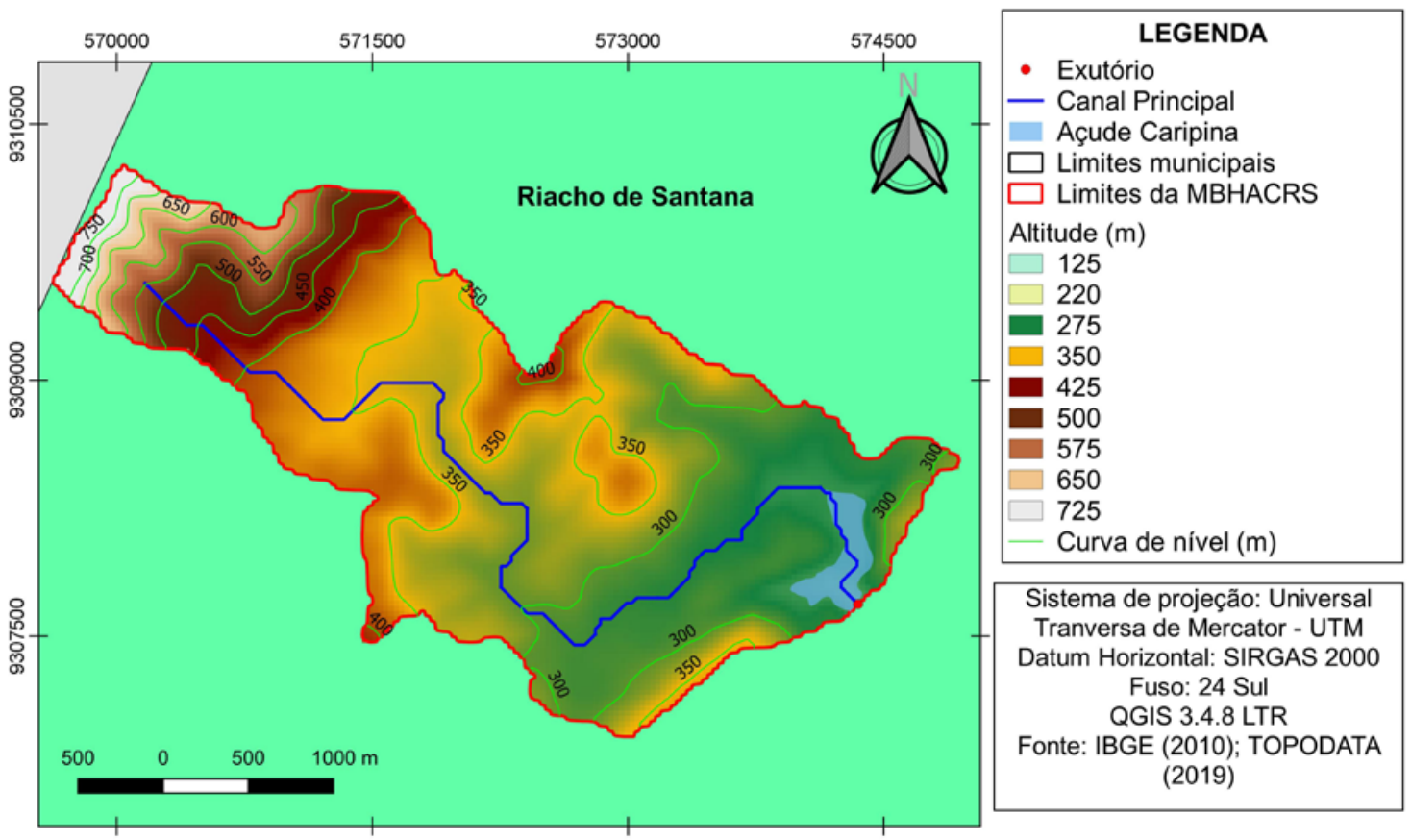

Sistema de projeção: Universal

Tranversa de Mercator - UTM

Datum Horizontal: SIRGAS 2000

Fuso: 24 Sul

QGIS 3.4.8 LTR

Fonte: IBGE (2010); TOPODATA (2019)

Figura 3 Mapa temático hipsométrico da MBHACRS, com curvas de nível e delimitação do canal principal e açude Caripina. 


\section{Carta da hierarquia fluvial da Microbacia Hidrográfica do Açude Caripina de Riacho de Santana/RN}

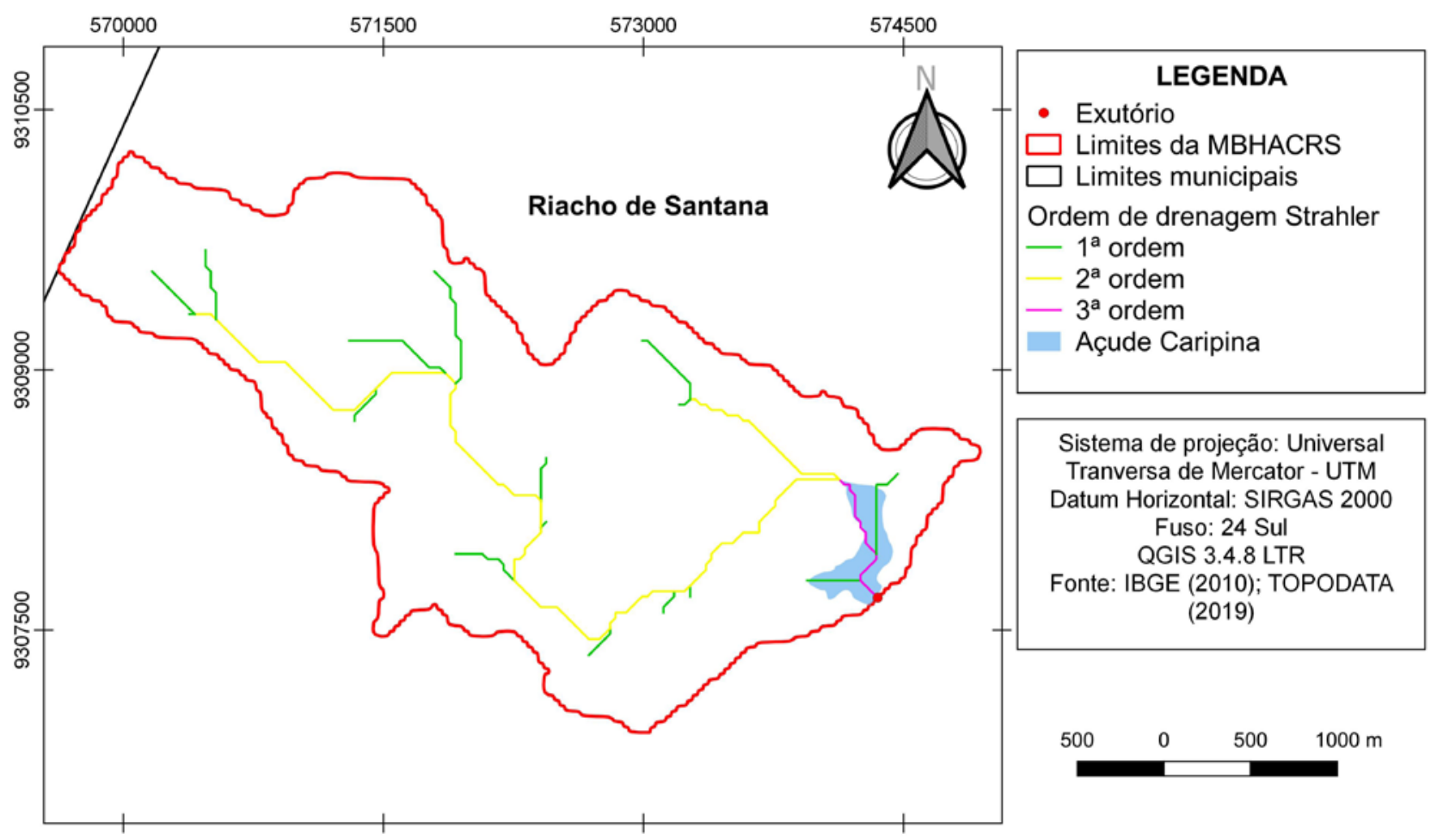

Figura 4 Mapa temático da hierarquia fluvial da MBHACRS.

Tabela 4 Hierarquia Fluvial e a relação entre o número e extensão dos canais em cada ordem da MBHACRS.

\begin{tabular}{ccc}
\hline Ordem dos canais & $\mathbf{N}^{\circ}$ de canais & $\begin{array}{c}\text { Extensão dos } \\
\text { canais }(\mathbf{k m})\end{array}$ \\
\hline $1^{\mathrm{a}}$ & 16 & 4,926 \\
$2^{\mathrm{a}}$ & 12 & 6,961 \\
$3^{\mathrm{a}}$ & 3 & 0,876 \\
Total & 31 & 12,763 \\
\hline
\end{tabular}

Em contrapartida, Silva, Bezerra \& Araújo (2017), obtiveram valores expressivos para esta análise, sendo que a declividade média da bacia (I) foi de 9,39\% e declividade do curso d'água principal (Ieq) de 7,41 m/ $\mathrm{km}$. Desta forma, indica tendência de baixa velocidade no escoamento superficial, aumentando a possibilidade da infiltração de água no solo para a Microbacia Hidrográfica do Açude Figueiredo do Alto Santo/CE.

\section{3 Áreas de Preservação Permanente de Encostas}

Conforme a legislação vigente, é necessário a delimitação de APP's com declividade superior a $45^{\circ}$. A preservação da vegetação proveniente da delimitação de APP's em encostas é fundamental por proporciona redução de deslizamentos e danos relacionados a outros fenômenos naturais ou artificiais, constituindo uma barreira natural de proteção do solo (Borelli \& Dal Bem 2015). As regiões com declividade suficientes para a delimitação de APP's na bacia de estudo estão expressas na Figura 6 .

Como o relevo da microbacia é caracterizado como ondulado, com declividade média compreendida na faixa 3 a 8\%, é esperado a pouca presença de APP's de encostas. Segundo Oliveira, Cessa \& Oliveira (2020), que desenvolveram a delimitação de APP's da Bacia Hidrográfica do Rio Urucuia, que se caracterizou com relevo suavemente ondulado, apenas $0,72 \%$ da área da 


\section{Carta de declividade da Microbacia Hidrográfica do Açude Caripina de} Riacho de Santana/RN

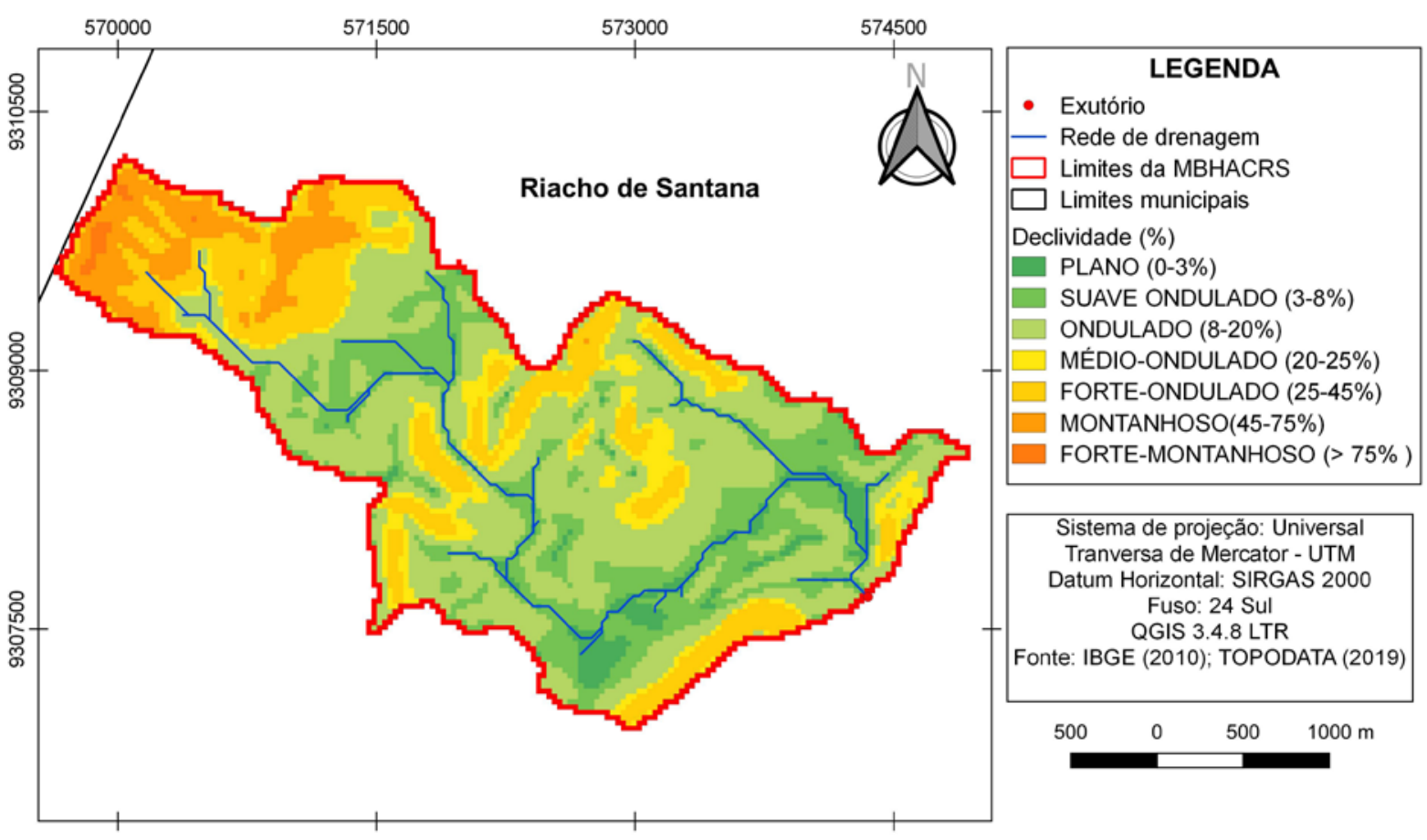

Figura 5 Declividade da MBHACRS segundo classificação da Embrapa (1979).

\section{Carta Imagem da delimitação das APP's de encostas da Microbacia Hidrográfica do Açude Caripina de Riacho de Santana/RN}
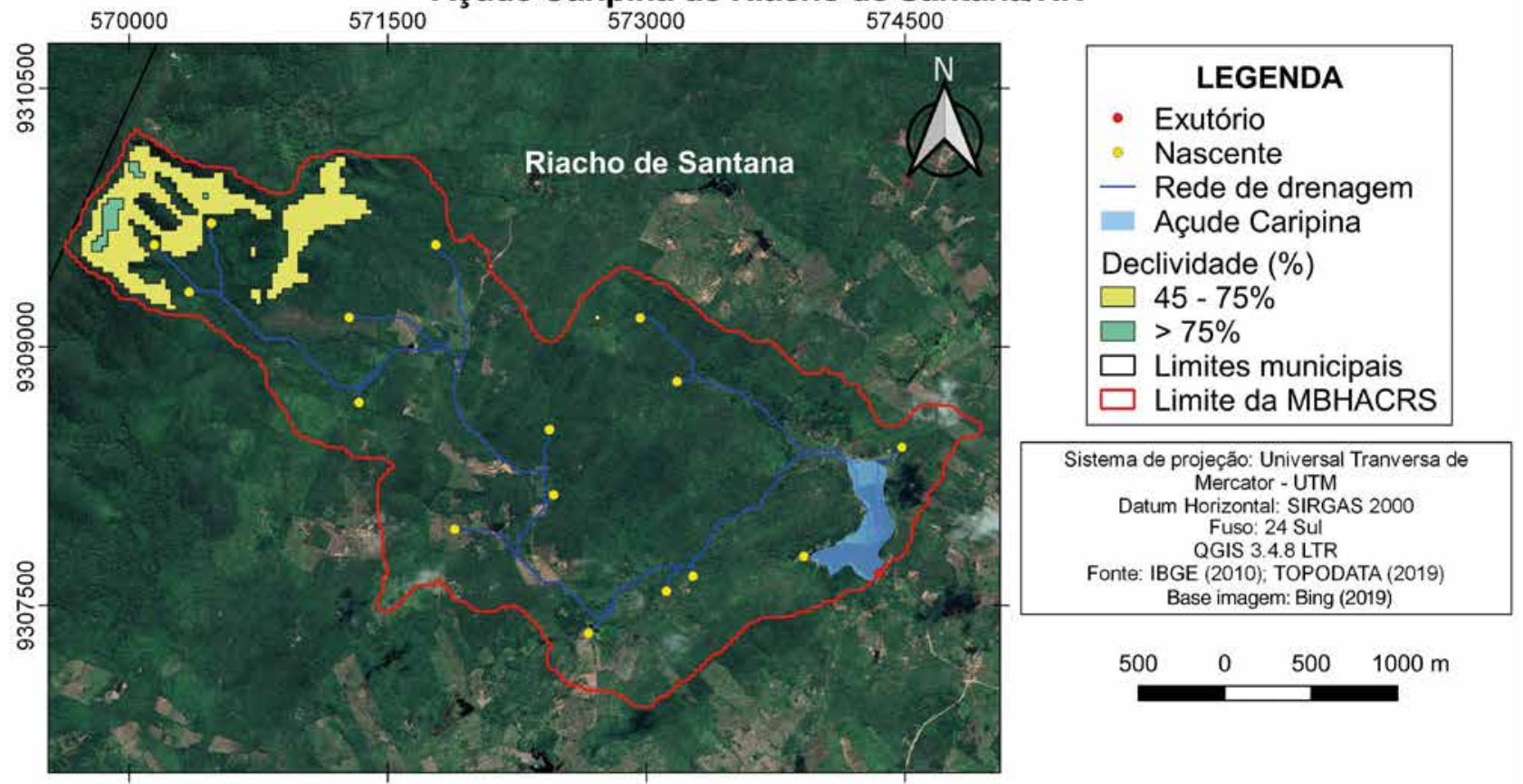

Figura 6 Delimitação de APP's de Encostas da MBHACRS. 
bacia apresentou declividade superior a $45^{\circ}$ necessária para delimitação. Algumas regiões sequer apresentam valores de declividade suficientes para delimitações.

Santos et al. (2017) mapearam as APP's da bacia do rio Piauitinga, no estado Sergipe, uma região que os autores identificaram como possuindo relevo predominantemente plano, não identificaram APP's pelo critério de declividades superiores a $45^{\circ}$. Resultado semelhante foi verificado por Encina et al. (2018) na bacia hidrográfica do Rio do Olho D’água, no estado do Mato Grosso do Sul, em que não foram identificadas APP's de encosta em virtude de o relevo ser caracterizado como "relativamente suave".

\section{4 Áreas de Preservação Permanente de Nascentes}

A análise da rede de drenagem da MBHACRS evidencia a presença de pontos com potenciais áreas de nascentes que necessitam de delimitação de APP's conforme legislação vigente. Diante deste resultado e utilizando os valores de demarcação estabelecidos na Lei No $12.651 / 2012$, as áreas de proteção permanente (APP's) foram delimitadas por circunferências com raio de $50 \mathrm{~m}$ a partir dos pontos de potencial presença de nascentes (Figura 7).

De acordo com Leal et al. (2017), a rede de drenagem depende da qualidade em que as nascentes se encontram.
A drenagem da microbacia necessita de fluxos d'água contínuos, distribuídos no tempo e em quantidade suficiente para garantir a eficiência do escoamento d'água. Fatores estes que corroboram com a necessidade de garantir a preservação destas áreas, além de assegurar a qualidade e disponibilidade dos recursos hídricos.

\section{5 Áreas de Preservação Permanente entorno de Lagos e Lagoas Naturais}

Como a microbacia em estudo está totalmente inserida na zona rural, a legislação que define a delimitação de APP's estabelece a distância de $100 \mathrm{~m}$ de entorno ao lago ou lagoa, de acordo com a localização geográfica e dimensão da área. Para a MBHACRS, que possui apenas o açude Caripina nessa conjuntura, definiu-se a APP visualizada na Figura 8.

Neste cenário, Oliveira, Silva \& Moura (2019) afirmam que as lagoas e áreas úmidas temporárias são críticas para o bem-estar da biodiversidade no domínio da caatinga, oferecendo meios de sobrevivência para muitas espécies aquáticas, vegetais e animais, tornando evidente a necessidade da delimitação de APP's conforme legislação vigente para proteção destes habitats frágeis (Giulietti et al. 2004).

\section{Carta Imagem da delimitação das APP's das nascentes da Microbacia Hidrográfica do Açude Caripina de Riacho de Santana/RN}

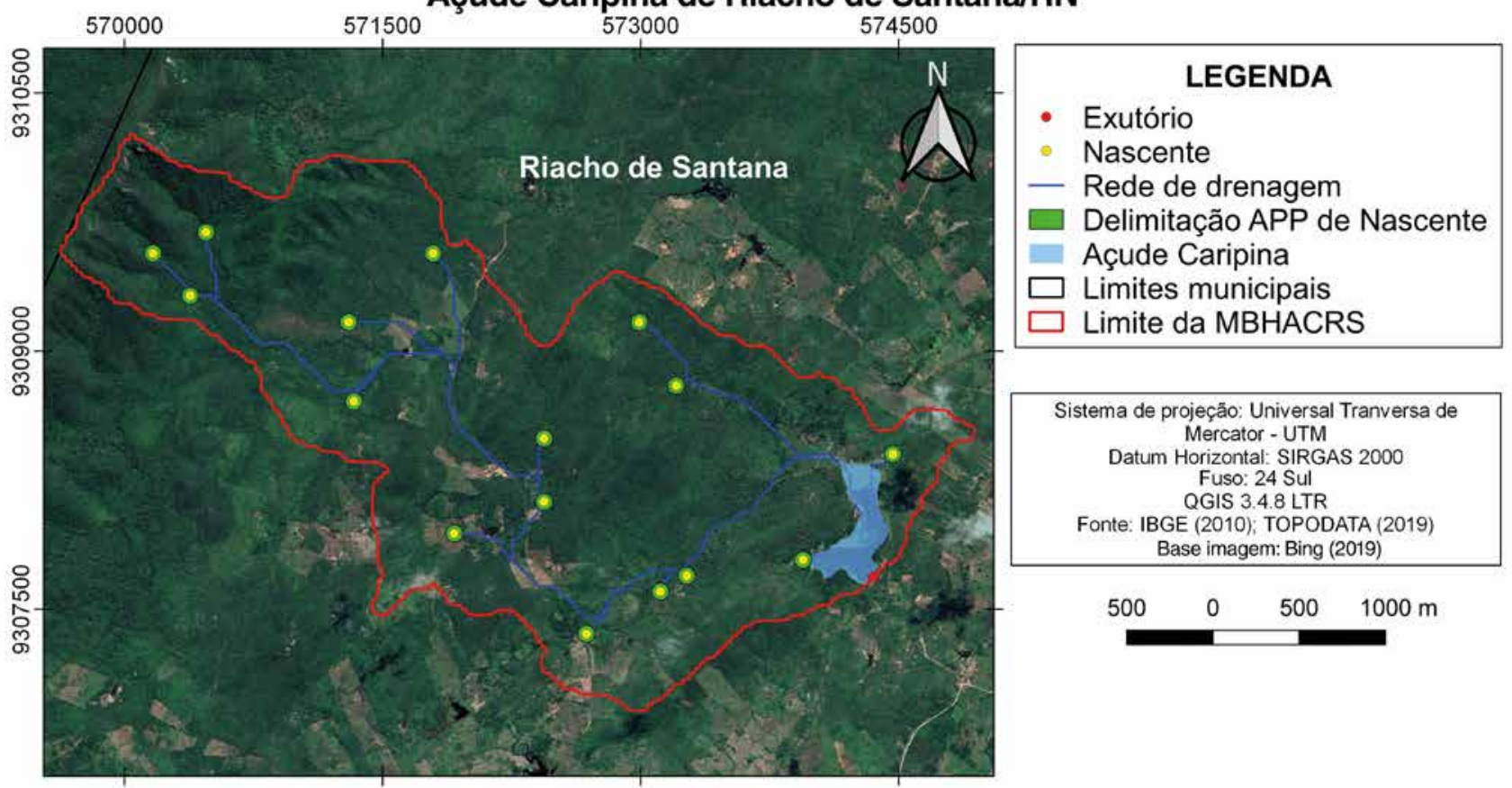

Figura 7 Delimitação das APP's das nascentes da MBHACRS. 


\section{Carta Imagem da delimitação das APP's do entorno de lagos da Microbacia Hidrográfica do Açude Caripina de Riacho de Santana/RN}

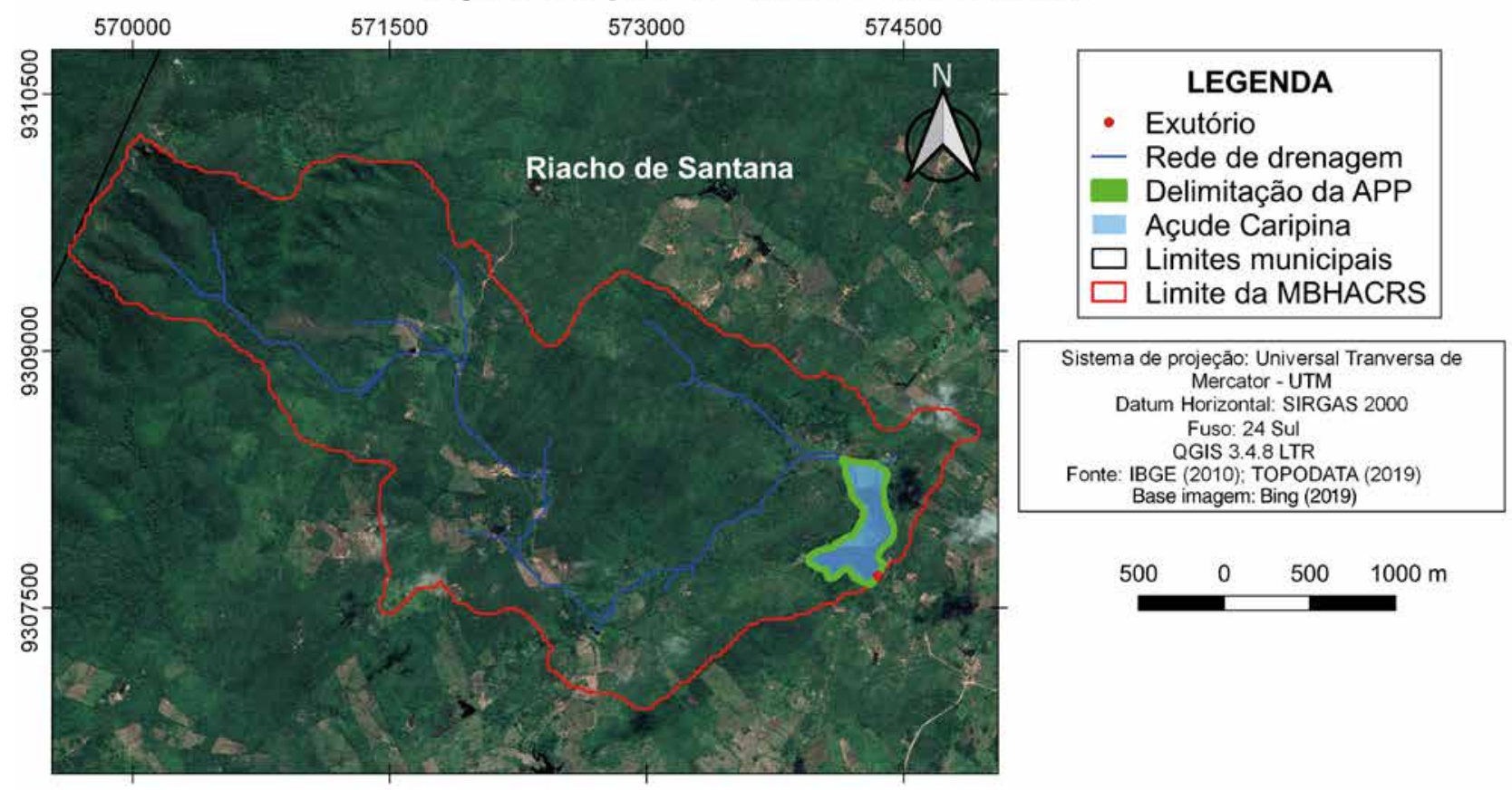

Figura 8 Delimitação de APP's de entorno de lagos da MBHACRS.

\section{Considerações Finais}

Em termos de estrutura, observou-se que a microbacia analisada tem baixa propensão para a ocorrência de enchentes, devido ao coeficiente de compacidade e ao fator de forma obtidos para a área como também as características naturais da referida área com um alto índice de escoamento superficial, consequência da declividade média da bacia e do curso de água.

A MBHACRS mostrou-se de grande importância para o desenvolvimento socioambiental da região, pois engloba o principal reservatório da cidade. Logo, apresenta características que justificam a necessidade de preservação da área, tais como, a aparição de supostas nascentes, além de APP's em encostas e no entorno dos lagos e lagoas, o que justifica o controle e a fiscalização sobra as atividades econômicas que são praticadas na região, principalmente no que diz respeito as práticas agrícolas, sendo que esta atividade apresenta grande propensão a degradação ambiental.

\section{Referências}

Alves, W.F. 2016, 'Estudo comparativo de métodos de regionalização hidrológica e desenvolvimento de um aplicativo para o gerenciamento de outorga de águas superficiais', Dissertação de Mestrado, Universidade de Brasília. https:// repositorio.unb.br/handle/10482/20492

Antoneli, V. \& Thomaz, E.L. 2007, 'Caracterização do meio físico da bacia do arroio Boa Vista-Guaramiranga (PR)', Caminhos de Geografia, vol. 8, no. 21, pp. 46-58.

Araújo, M.S. 2017, 'Evolução dos canais fluviais: morfometria e sedimentologia na bacia hidrográfica do rio Santo Antônio, Serra da Canastra-MG', Dissertação de Mestrado, Universidade Federal de Uberlândia. https://repositorio.ufu. br/handle/123456789/19956

Banco de Dados de Informações Ambientais 2021, Consulta: Geomorfologia, IBGE, Brasília, viewed 2 January 2020, $<$ https://bdiaweb.ibge.gov.br/\#/consulta/geomorfologia $>$.

Beltrame, A.V. 1994, Diagnóstico do meio físico de bacias hidrográficas: modelo e aplicação. UFSC, Florianópolis.

Bezerra, J.M., Rego, V.G.S., Possas, J.M.C., Souza, E.P. \& Fernandes Neto, S. 2015, 'Análise morfométrica da microbacia hidrográfica Riacho das Piabas/PB', paper presented to 
Congresso Técnico Científico da Engenharia e da Agronomia CONTECC, Fortaleza, pp. 1-4.

Bezerra, M.B. 2016, 'A crise hídrica como reflexo da seca: o Nordeste Setentrional em alerta', Revista De Geociências Do Nordeste, vol. 2, no. 1, pp. 623-32.

Borelli, I. \& Dal Bem, M.V. 2015, 'Uso do solo nas áreas de preservação permanente em encostas e topos de morros no perímetro urbano de Francisco Beltrão-PR no ano de 2009', Trabalho de Conclusão de Curso, Universidade Tecnológica Federal do Paraná, http://repositorio.roca.utfpr.edu.br/jspui/ bitstream/1/6950/1/FB_COEAM_2015_2_06.pdf

Cardoso, C.A., Dias, H.C.T., Soares, C.P.B. \& Martins, S.V. 2006, 'Caracterização morfométrica da bacia hidrográfica do rio Debossan, Nova Friburgo, RJ', Revista Árvore, vol. 30, no. 2, pp. 241-8. https://doi.org/10.1590/S0100-67622006000200011

Christofoletti, A. 1970, 'Análise morfométrica das bacias hidrográficas do Planalto de Poços de Caldas (MG)', Tese de Doutorado, Universidade Estadual Paulista, https:// www.scirp.org/(S(i43dyn45teexjx455qlt3d2q))/reference/ ReferencesPapers.aspx?ReferenceID $=1740285$

Código Florestal 2012 (DOU, Brasil), <http://www.planalto.gov. br/ccivil_03/_ato2011-2014/2012/lei/112651.htm>.

Embrapa 1979, Manual de métodos de análise de solo, Rio de Janeiro, viewed 21 october 2019, <https://www. agencia.cnptia.embrapa.br/Repositorio/Manual+de+ Metodos_000fzvhotqk02wx5ok0q43a0ram31wtr.pdf $>$.

Encina, C.C.C., Marques, M.R., Diodato, M.A., Pereira, L.E., Albrez, E.D.A., Oliveira, A.P.G., Mioto, C.L., Miranda, V.R., Miranda, L.M., Coelho, L.S., Dalmas, F.B. \& Paranhos Filho, A.C. 2018, 'Geotecnologias Aplicadas à Análise Ambiental da Bacia Hidrográfica do Rio Olho d’Água, Município de Jardim, Mato Grosso do Sul - Brasil', Anuário do Instituto de Geociências, vol. 41, no. 2, pp. 577-84. https://doi. org/10.11137/2018_2_577_584

Farias, J.F. \& Silva, E.V. 2015, 'Compartimentação geomorfológica da bacia hidrográfica do Rio Palmeira - Ceará: subsídios ao planejamento ambiental', Geosaberes: Revista de Estudos Geoeducacionais, vol. 6, no, 1, pp. 149-63.

Fraga, M.S., Ferreira, R.G., Silva, F.B., Vieira, N.P.A., Silva, D.P., Barros, F.M. \& Martins, I.S.B. 2014, 'Caracterização morfométrica da bacia hidrográfica do rio Catolé Grande, Bahia, Brasil', Nativa, vol. 2, no. 4, pp. 214-8, http://dx.doi. org/10.14583/2318-7670.v02n04a05

Giulietti, A.M., Bocage Neta, A.L., Castro, A.A.J.F., GamarraRojas, C.F.L., Sampaio, E.V.S.B., Virgínio, J.F., Queiroz, L.P., Figueiredo, M.A., Rodal, M.J.N., Barbosa, M.R.V. \& Harley, R.M. 2004, Diagnóstico da vegetação nativa do bioma Caatinga, Ministério do Meio Ambiente, Brasília.

Instituto Brasileiro de Geografia e Estatística 2017, Divisão regional do Brasil em regióes geográficas imediatas e regiões geográficas intermediárias: 2017, 1st edn, IBGE, Rio de Janeiro, viewed 26 October 2019, < https://biblioteca.ibge. gov.br/visualizacao/livros/liv100600.pdf $>$.
Instituto de Desenvolvimento Sustentável e Meio Ambiente 2008. Perfil dos municipios do RN. Natal, viewed 26 October 2019, $<$ http://www.idema.rn.gov.br/Conteudo.asp?TRAN=PASTA $\mathrm{C} \& \mathrm{TARG}=983 \& \mathrm{ACT}=\& \mathrm{PAGE}=\& \mathrm{PARM}=\& \mathrm{LBL}=>$.

Leal, M.S., Tonello, K.C., Dias, H.C.T. \& Mingoti, R. 2017, 'Caracterização hidroambiental de nascentes', Revista Ambiente \& Água, vol. 12, no 1, pp. 146-55, https://doi. org/10.4136/ambi-agua.1909

Lorenzon, A.S., Fraga, M.D.S., Moreira, A.R., Uliana, E.M., Silva, D.D.D., Ribeiro, C.A.A.S. \& Borges, A.C. 2015, 'Influência das características morfométricas da bacia hidrográfica do rio Benevente nas enchentes no município de Alfredo ChavesES', Revista Ambiente \& Água, vol. 10, no. 1, pp. 195-206. https://doi.org/10.4136/ambi-agua.1475

Magalhães, L.C.B., Chaves, M.L.Q., Queiroz Junior, A.B. \& Bezerra, J.M. 2020, 'Estudo Morfométrico da Microbacia Hidrográfica do Açude Canafístula em Iracema - CE' in Seabra, G. (ed.), Educação Ambiental - Cenários atuais da saúde ambiental e humana, Ituiutaba, pp. 1-13.

Mello, C.R. \& Silva, A.M. 2013, Hidrologia: Princípios e Aplicações em Sistemas Agrícolas, 1st edn, UFLA, Minas Gerais.

Oliveira, C.D.L., Silva, A.P.A. \& Moura, P.A.G. 2019, 'Distribuição e Importância das Unidades de Conservação no Domínio Caatinga', Anuário do Instituto de Geociências, vol. 42, no. 1, pp. 425-9. http://dx.doi.org/10.11137/2019_1_425_429

Oliveira, C.M.M., Cessa, R.M.A. \& Oliveira, J.A.M. 2020, 'Delimitação de Áreas de Preservação Permanente em Diferentes Resoluções Espaciais', Anuário do Instituto de Geociências, vol. 43, no. 1, pp. 171-80. http://dx.doi. org/10.11137/2020_1_171_180

Política Nacional de Recursos Hídricos 1997 (DOU, Brasil), http:// www.planalto.gov.br/ccivil 03/leis/19433.htm.

Rodrigues, R.S.S., Fernandes, L.L., Crispim, D.L., Vieira, A.S. \& Pessoa, F.C.L. 2016, 'Caracterização morfométrica da bacia hidrográfica do igarapé da Prata, Capitão Poço, Pará, Brasil', Revista Verde de Agroecologia e Desenvolvimento Sustentável, vol. 11, no. 3, pp. 143-50. https://doi.org/10.18378/rvads. v11i3.4313

Santos, W.A., Cruz, J.F., Almeida, A.Q., Mello, A.A., Santos, R.B. \& Loureiro, D.C. 2017, 'Conflito de uso da terra em áreas de preservação permanentes da bacia do rio Piauitinga, Sergipe, Brasil', Revista de Ciências Agrárias - Amazonian Journal of Agricultural and Environmental Sciences, vol. 60, no. 1, pp. 19-24, http://dx.doi.org/10.4322/rca.2281

Silva, W.B, Bezerra, J.M \& Araújo, C.S.P. 2017 'Caracterização Morfométrica da Bacia Hidrográfica do Açude Figueiredo do Alto Santo/CE', paper presented to Encontro Regional de Sustentabilidade e Políticas Públicas, Pau dos Ferros.

Souza, J.O.P., Almeida, J.D.M. \& Correa, A.C.B. 2015, 'Caracterização e espacialização da precipitação em bacia hidrográfica com relevo complexo: Sertão Central Pernambucano -Bacia do Riacho do Saco', Revista de 
Geografia (UFPE), vol. 32, no. 2, pp. 106-26, https://doi. org/10.51359/2238-6211.2015.229135

Strahler, A.N. 1957, 'Quantitative analysis of watershed geomorphology', Eos, Transactions American Geophysical Union, vol. 38, no. 6, pp. 913-20, https://doi.org/10.1029/ TR038i006p00913
Tonello, K.C., Dias, H.C.T., Souza, A.L., Ribeiro, C.A.A.S. \& Leite, F.P. 2006, 'Morfometria da bacia hidrográfica da Cachoeira das Pombas, Guanhães - MG', Revista Árvore, vol. 30, no. 1, pp. 849-57, https://doi.org/10.1590/S010067622006000500019

Villela, S.M. \& Mattos, A. 1975, Hidrologia Aplicada, McGraw - Hill do Brasil, São Paulo.

\section{Como citar:}

Roque, F.S., Bezerra, J.M., Costa, T.T., Rêgo, A.T.A., Lima, R.I.B.R, Souza, R.S., Queiroz Júnior, A.B. \& Costa, H.C.G. 2021, 'Zoneamento Ambiental da Microbacia Hidrográfica do Açude Caripina no Município de Riacho de Santana, RN', Anuário do Instituto de Geociências, vol. 44: 38660. https://doi.org/10.11137/1982-3908_2021_44_38660 